\title{
LA APLICACIÓN DEL RBII BIS EN MATERIA DE RESPONDABILIDAD PARENTAL POR LOS TRIBUNALES ESPAÑOLES: COMENTARIO CRÍTICO AL AAP BARCELONA DE 23 DE JULIO DE 2020*
}

\author{
THE APPLICATION OF THE RBII BIS IN THE AREA \\ OF PARENTAL RESPONSIBILITY BY THE SPANISH COURTS: \\ CRITICAL COMMENTARY ON THE AAP BARCELONA \\ OF 23 JULY 2020
}

\author{
María Jesús SÁnchez CANO \\ Profesora Ayudante Doctora (Universidad San Jorge) \\ Magistrado Suplente
}

Recibido: 15.06.2021// Aceptado: 14.07.2021

DOI: https://doi.org/10.20318/cdt.2021.6306

\begin{abstract}
Resumen: El presente trabajo analizará algunos de los inconvenientes con los que se encuentran los tribunales españoles cuando se presenta ante ellos un litigio en materia de responsabilidad parental con elementos transfronterizos, para cuya solución deberán de aplicarse las soluciones que establece el RBII bis. A tal fin, se llevará a cabo un comentario crítico del AAP Barcelona de 23 de julio de 2020, en el cual se plantean cuestiones relativas a la competencia judicial internacional, la litispendencia internacional y la eficacia en España de las resoluciones dictadas por los órganos jurisdiccionales de un Estado Miembro en relación con la guarda, custodia, derecho de visitas y alimentos de un menor de edad.

Palabras clave: responsabilidad parental, alimentos, litispendencia, competencia judicial internacional.

Abstract: This paper will analyze some of the disadvantages encountered by the Spanish courts when a parental responsibility dispute with cross-border elements is brought before them, for the solution of which the solutions established by the RBII bis must be applied. To this end, a critical commentary will be made on the AAP Barcelona of 23 July 2020, in which questions of international jurisdiction are raised, international lis pendens and the effectiveness in Spain of judgments given by the courts of a Member State in relation to the custody, visiting rights and maintenance of a minor.

Keywords: parental responsibility, maintenance, lis pendens, international jurisdiction.

Sumario: Breve introducción general. II. El AAP Barcelona 23 de julio 2020: Cuestiones litigiosas. 1. Antecedentes: El Auto de 16 de septiembre de 2019, dictado por el Juzgado de Primera Instancia ${ }^{\circ} 14$ de Barcelona. 2. La resolución del Tribunal "ad quem". III. Normativa aplicable al caso estudiado. 1. Competencia judicial internacional. 2. Supuestos de litispendencia internacional. 3. Eficacia en España de resoluciones extranjeras en las materias analizadas: Instrumentos legales aplicables. IV. Análisis del fallo del AAP Barcelona 23 julio 2020. V. Reflexiones finales.
\end{abstract}

*El presente trabajo ha sido elaborado en el marco del Grupo Consolidado de Investigación del Gobierno de Aragón "Ius Familiae", IP Carlos Martínez de Aguirre Aldaz. 


\section{Breve introducción general}

1. La globalización, el progreso tecnológico y los movimientos migratorios han favorecido un incremento de las situaciones privadas transfronterizas, provocando una internacionalización de las relaciones familiares y en consecuencia, también un aumento de los litigios en asuntos de familia, tales como los relativos a la responsabilidad parental, derechos de visitas y alimentos, respecto de los hijos menores de edad.

2. Sobre este particular, es fácil suponer que la presencia de un elemento extranjero en este tipo de demandas añade un plus de complejidad, en tanto que sujetan la situación a sistemas jurídicos de distintos países, planteando lo que se denomina conflictos de jurisdicción, cuya resolución se dificulta todavía más cuando existen varias demandas pendientes ante Tribunales de diferentes Estados. Se plantea, por tanto, la necesidad de dirimir cuál de estos Tribunales resultan competentes para conocer de la controversia.

3. Las dificultades también se hacen notar cuando existe una resolución dictada por órganos jurisdiccionales extranjeros, en tanto que resulta necesario su previo reconocimiento en España para que surta efectos en nuestro país.

4. El presente trabajo analizará algunos de los inconvenientes con los que se encuentran los tribunales españoles cuando se presenta ante ellos un litigio en materia de responsabilidad parental con elementos transfronterizos, para cuya solución deberán de aplicarse las soluciones que establece el RBII bis ${ }^{1}$. A tal fin, se llevará a cabo un comentario crítico del AAP Barcelona de 23 de julio de 2020, en el cual se plantean cuestiones relativas a la competencia judicial internacional, la litispendencia internacional y la eficacia en España de las resoluciones dictadas por los órganos jurisdiccionales de un Estado Miembro en relación con la guarda, custodia, derecho de visitas y alimentos de un menor de edad.

\section{EI AAP Barcelona 23 de julio 2020²: Cuestiones litigiosas}

5. Con carácter previo parece oportuno exponer los extremos más relevantes del litigio. A tal fin, se dividirá el presente apartado en dos epígrafes diferentes, en los cuales se distinguirán las cuestiones resueltas en primera instancia de las analizadas vía recurso de apelación. En síntesis, la controversia se centra en resolver si los Tribunales españoles disponen de competencia judicial internacional para el enjuiciamiento de caso, así como si debe admitirse la existencia de litispendencia internacional y el valor que ha de otorgarse a una resolución dictada por los Tribunales franceses, cuya vigencia ha sido reconocida por la propia Audiencia Provincial con anterioridad.

\section{Antecedentes: El Auto de 16 de septiembre de 2019, dictado por el Juzgado de Primera Instan- cia $\mathbf{n}^{0} 14$ de Barcelona.}

6. El asunto resuelto por la Audiencia Provincial de Barcelona trae causa de la reclamación de guarda, custodia y alimentos en relación con hijos menores no matrimoniales, no consensuados, formulada ante los Juzgados de Primera Instancia de la mencionada ciudad por la madre de una niña menor de edad. De los antecedentes se desprende que anteriormente, tanto la madre como la hija residían en Francia, si bien, en el momento de interposición de la demanda, la menor se había trasladado a España, conviviendo con su progenitora en el domicilio de ésta. En la demanda, la madre interesa los siguientes extremos:

\footnotetext{
${ }^{1}$ Reglamento (CE) no 2201/2003 del Consejo, de 27 de noviembre de 2003, relativo a la competencia, el reconocimiento y la ejecución de resoluciones judiciales en materia matrimonial y de responsabilidad parental, por el que se deroga el Reglamento (CE) no 1347/2000 («DOUE» núm. 338, de 23 de diciembre de 2003).

2 AAP Barcelona núm. 6369/2020, 23 julio (ECLI:ES:APB:2020:6369ª).
} 
$\left.1^{\circ}\right)$ Que la patria potestad de los progenitores sea compartida.

$2^{\mathrm{a})}$ Que le sea atribuida a la madre la guarda de la menor.

$3^{\circ}$ ) Que se fije un régimen de visitas a favor del padre.

$\left.4^{\circ}\right)$ Que se establezca el domicilio de la menor en el de la madre.

$\left.5^{\circ}\right)$ Y que se imponga al padre una pensión alimenticia para la hija de 650 euros mensuales y el abono de la totalidad de los gastos extraordinarios de la menor.

7. Por su parte, el padre de la menor planteó declinatoria ante los Tribunales españoles, con fundamento en los arts. 39 y 63 y 64 de la LEC $^{3}$, solicitando se dictase auto por el cual el Juzgado de Primera Instancia se abstuviera de conocer del asunto y en consecuencia, declarase el sobreseimiento del procedimiento principal y de medidas provisionales por falta de competencia judicial internacional. Todo ello, por entender que, en aplicación del art. 8 RBII bis, dicha competencia debería de recaer en los tribunales franceses, correspondientes a la residencia habitual de la hija común de los litigantes.

8. El Juzgado de Primera Instancia estimó la declinatoria por falta de competencia judicial internacional de los Tribunales españoles, al mismo tiempo que acordó la suspensión del curso del proceso, sobre la base del art.39 LCJIMC ${ }^{4}$. A este respecto, explica el Juzgador "a quo", que existe una resolución anterior, de fecha 9 de abril de 2019, dictada por un Juzgado de Primera Instancia, en la que dicho órgano jurisdiccional se declara competente para enjuiciar la demanda sobre la guarda de la menor y que, además, existe otra resolución de un Juzgado español que se declaró incompetente internacionalmente en favor de los Tribunales franceses, con la finalidad de evitar resoluciones contradictorias.

\section{La resolución del Tribunal "ad quem"}

9. La Audiencia Provincial de Barcelona resuelve el recurso de apelación interpuesto por la madre de la menor contra la resolución decretada en Primera Instancia, cuyos fundamentos se acaban de explicar.

10. EL Tribunal "ad quem" pone en evidencia que esa misma Sala dictó con anterioridad, en fecha 13 de marzo de 2020, un auto resolviendo un recurso de apelación precedente, en el que, entre otros pronunciamientos, reconoció la plena vigencia en España de una resolución dictada por el Tribunal de Apelación de Montpelier en fecha 17 de enero de 2020. La resolución francesa declaró atribuir conjuntamente el ejercicio de la patria potestad sobre la menor a ambos progenitores, fijando el lugar de residencia de la niña en el domicilio de la madre y estableciendo un régimen de visitas en favor del padre.

11. La Audiencia Provincial comienza diferenciando aquellos supuestos meramente internos de los que presentan un elemento internacional. Así, la Sala destaca que cuando las partes son nacionales y residen en España, especialmente los menores, las normas de competencia están sujetas a la normativa procesal española, que el Tribunal identifica con las que se contemplan en la LOPJ $^{5}$ y en la LEC). Mientras que, si existe un elemento internacional en la situación, la Audiencia Provincial remite de forma directa o indirecta, a la LCJIMC o a los convenios internacionales y más en concreto, en el caso que nos ocupa, a la normativa de la Unión Europea, que la Sala considera prevalente.

12. Por consiguiente, el Tribunal "ad quem" acude a los arts. 8 y ss del RBII bis para determinar la competencia judicial internacional en el supuesto examinado y específicamente al art.8.1, que, en materia de responsabilidad parental, otorga competencia a los órganos jurisdiccionales del Estado miembro de la residencia habitual del menor en el momento en el que se presenta el asunto ante dicho órgano jurisdiccional. Asimismo, explica la Audiencia Provincial, que de producirse un cambio en la residencia habitual del

\footnotetext{
${ }^{3}$ Ley 1/2000, de 7 de enero, de Enjuiciamiento Civil («BOE» núm. 7, de 08/01/2000).

${ }^{4}$ Ley 29/2015, de 30 de julio, de cooperación jurídica internacional en materia civil («BOE» núm. 182, de 31/07/2015).

${ }^{5}$ Ley Orgánica 6/1985, de 1 de julio, del Poder Judicial («BOE» núm. 157, de 02/07/1985).
} 
menor, serán los juzgados de esta nueva residencia los competentes, con la única excepción que recoge el art. 9 del mismo Reglamento, que prevé una prórroga de tres meses de los juzgados de la anterior residencia del menor, pese al cambio de residencia, si bien sólo para peticiones relativas al derecho de visita.

13. En el momento de resolver, el Tribunal "ad quem" toma en consideración los siguientes datos, para concluir que la competencia judicial internacional corresponde a los tribunales de la residencia actual de la niña, es decir, los españoles:

$1^{\circ}$ ) La controversia no se centra en la modificación del derecho de visitas, sino en el ejercicio de la responsabilidad parental.

$2^{\circ}$ ) El traslado de la niña a nuestro país se produjo legalmente y con anterioridad a que por otro órgano jurisdiccional, francés o español, se hubiese dictado resolución alguna atribuyendo la guarda de la menor a alguno de sus progenitores o que prohibiera la salida de la misma de Francia.

14. En cuanto a la decisión dictada por el Tribunal de apelación de Montpellier, independiente o no de que sea definitiva, la Audiencia entiende que la misma no resuelve la totalidad de las medidas solicitadas por la madre en la demanda que da origen al procedimiento enjuiciado y en consecuencia, han de ser objeto de pronunciamiento por el Juzgado de Primera Instancia, una vez que se ha declarado su competencia judicial internacional para el conocimiento del litigio.

\section{Normativa aplicable al caso estudiado}

15. En primer lugar, para determinar los instrumentos legales que resultan aplicables a la resolución del litigio hay que atender a las pretensiones de las partes, con objeto de verificar si la categoría jurídica implícita en las mismas puede subsumirse en el ámbito de aplicación material de la normativa que seguidamente se estudiará. Así, en primer lugar, hay que diferenciar, por un lado, el régimen de la patria potestad, la atribución de la guarda de la menor, el establecimiento de un régimen de visitas en favor del padre y el pronunciamiento relativo al domicilio de la menor; y por otro, la pensión de alimentos que solicita la madre para la niña.

16. En este sentido, hay que puntualizar que el primer bloque de cuestiones señaladas- patria potestad, derechos de guarda y custodia, así como de visita ${ }^{6}$ y establecimiento de domicilio de la menor, conforman el concepto más amplio de responsabilidad parental ${ }^{7}$. Así se desprende de la normativa más relevante de Derecho Internacional privado en materia de protección de menores, es decir, tanto del art.1.2 y el art.2.7 RBII bis ${ }^{8}$ en relación con los apartados 9 y 10 del citado precepto, como el art.1.2 CH 1996 9.

\footnotetext{
${ }^{6}$ Sobre este particular, véase STJUE 31 mayo 2018, (C-335/17, ECLI:EU:C:2018:359).

7 Tras la reforma efectuada por la Ley 26/2015, de 28 de julio, de modificación del sistema de protección a la infancia y a la adolescencia (BOE núm. 180, 29 julio 2015), se ha incorporado el término responsabilidad parental a nuestra normativa de producción interna. Sirvan de ejemplo los arts.9.4, y 154 Cc, entre otros. Está claro, por tanto, que el concepto de responsabilidad parental incluye la patria potestad tal como se concibe en el Derecho Civil español. Vid. A.L. Calvo Caravaca y J. Carrascosa González, Derecho Internacional Privado, Vol.II, Décimoctava edición, 2018, Granada, Comares, 2018, p.455.

${ }^{8}$ En virtud del 2.7 RBII bis, el concepto de responsabilidad parental abarca "los derechos y obligaciones conferidos a una persona física o jurídica en virtud de una resolución judicial, por ministerio de la ley o por un acuerdo con efectos jurídicos, en relación con la persona o los bienes de un menor". Además, el citado precepto, en sus apartados 9 y 10, remarca que dentro del término responsabilidad parental se incluyen, particularmente, los derechos de custodia y visita. El TJUE ha venido interpretando el concepto de responsabilidad parental de manera amplia, señalando que la lista de materias que enumera el art.2.1 RBI II bis no es exhaustiva, sino "meramente indicativa", como se deduce del uso de la expresión "en particular". En este sentido, pueden consultarse las siguientes resoluciones del TJUE: STJUE (Gran Sala) 27 de noviembre 2007 (C435/06, ECLI: EU:C:2007), STJUE (Sala Segunda) 26 abril 2012 (C92/12 PPU, ECLI:EU:C:2012:255), STJUE (Sala Cuarta) 21 octubre 2015 (C-215/15, ECLI:EU:C:2015:710) Y STJUE 31 mayo 2018 (C-335/17, ECLI:EU:C:2018:359).

${ }^{9}$ Convenio relativo a la competencia, la ley aplicable, el reconocimiento, la ejecución y la cooperación en materia de responsabilidad parental y de medidas de protección de los niños, hecho en La Haya el 19 de octubre de 1996 (BOE Núm. 291, 2
} 
16. No obstante lo dicho, la solicitud de pensión de alimentos no tendría cabida dentro del concepto de responsabilidad parental, habida cuenta que tanto el art.1.3.c) RBII bis como el art.4.e) CH 1996 excluyen de su ámbito de aplicación a las obligaciones de alimentos. Luego, en el caso que nos ocupa, la reclamación de alimentos estaría amparada por lo dispuesto en el Reglamento (CE) no 4/2009 del Consejo, de 18 de diciembre de 2008, relativo a la competencia, la ley aplicable, el reconocimiento y la ejecución de las resoluciones y la cooperación en materia de obligaciones de alimentos.

\section{Competencia judicial internacional}

16. En segundo término, por lo que respecta a la determinación de la competencia judicial internacional en materia de responsabilidad parental parece oportuno comenzar precisando el orden de prevalencia de los diferentes textos normativos en vigor en nuestro país, que son los siguientes: RBII bis, CH 1996y el art.22 quáter LOPJ. En este punto, hay que atender a los siguientes criterios para determinar cuál de estos textos legales resulta aplicable, tomando en consideración el lugar de residencia habitual del menor ${ }^{10}$ :

a) Si el menor reside habitualmente en un Estado miembro del RBII bis se aplicará este Reglamento con preferencia al CH 1996 (art.61 RBII bis) y al art.22 quáter LOPJ. El RBII bis no discierne si la minoría de edad ha de fijarse en una determinada edad, como pudieran ser los dieciocho años de edad. Por este motivo, cabe concluir que, a los efectos del RBII bis, la mayoría de edad vendrá determinada conforme a la ley personal del sujeto, que en España se fija de acuerdo con el art.9.1 Cc.

b) El CH 1996 operará cuando el menor no resida habitualmente en un Estado miembro, pero haya fijado su residencia habitual en un Estado parte del CH 1996. El art. 2 del Convenio indica que el mismo se aplica a los niños desde su nacimiento y hasta alcanzar la edad de dieciocho años. La competencia internacional se establecerá también a través del CH 1996 en el supuesto de que el menor no resida habitualmente ni en un Estado miembro del RBII bis ni en un Estado parte del CH 1996. Sin embargo, aquí hay que tener en cuenta que el art.12.4 RBII bis permite aplicar este foro a un menor con residencia habitual en el territorio de un tercer Estado que no sea parte contratante del CH 1996, en beneficio del menor y particularmente, cuando no resulte posible incoar un procedimiento en el tercer Estado en cuestión.

c) Con carácter residual, cuando no entren en juego ni el RBII bis ni el CH 1996, podrá aplicarse el art.22 quáter LOPJ. Es decir, si se trata de un mayor de dieciocho años (art.2 CH 1996), pero, menor de edad conforme a su ley personal (art.9.1 Cc), y que no reside en un Estado miembro.

d) Junto a ello, tampoco hay que olvidar que pudiera darse el caso de que resultase aplicable el RBII bis y sin embargo, del mismo no fuese posible deducir la competencia judicial internacional de ninguna autoridad de ningún Estado miembro, en cuyo caso, correspondería acudir al CH 1996. Sólo en el supuesto de que no pudiera determinarse la competencia con arreglo al Convenio, entraría en juego el art.22 quáter LOPJ (art.14 RBII bis), de tal manera que si dicho artículo no atribuyese competencia a las autoridades y tribunales españoles, estos deberían declararse de oficio incompetentes internacionalmente ${ }^{11}$.

diciembre 2010). El art. 1.2 CH 1996 establece que la noción de responsabilidad parental comprende "la autoridad parental o cualquier otra relación de autoridad análoga que determine los derechos, poderes y obligaciones de los padres, tutores o de otro representante legal respecto a la persona o los bienes del niño". Igualmente, el art. 3, entre las medidas cubiertas por el Convenio, contempla "la atribución, ejercicio y privación total o parcial de la responsabilidad parental, así como su delegación", el derecho de guarda, así como el derecho de visita, introduciendo "el derecho de trasladar al niño durante un periodo limitado de tiempo a un lugar distinto del de su residencia habitual".

${ }_{10}$ A este respecto, se ha tenido en cuenta lo dispuesto en A.L. Calvo Caravaca y J. Carrascosa González, "Tema XV: Protección de menores", en A.L. Calvo Caravaca y J. Carrascosa González (Dir.), Compendio de Derecho Internacional Privado, Murcia, 2019, p.390.

11 A.L. Calvo Caravaca y J. Carrascosa González, Derecho Internacional Privado...cit., p. 432. 
17. Por lo que respecta al presente trabajo, interesa poner de manifiesto que el Reglamento establece como regla general, en su art. ${ }^{12}$, que, en materia de responsabilidad parental, son competentes internacionalmente los órganos jurisdiccionales del Estado miembro en el que el menor tenga su residencia habitual en el momento de presentación del asunto ante dichas autoridades ${ }^{13}$. Ello, con las excepciones de los arts.9 y 10 del propio Reglamento, en las cuales los órganos jurisdiccionales del Estado miembro en el que el menor tenía su residencia habitual anterior mantienen su competencia ${ }^{14}$.

18. En este punto, hay que observar que el RBII bis no contempla una definición de "residencia habitual"15. Sin embargo, esta laguna ${ }^{16}$ ha sido integrada por el TJUE, que ha dejado bien sentado que, a los efectos de la aplicación del art.8 RBII bis y siguiendo la idea proveniente de los Convenios de la Conferencia de La Haya de Derecho Internacional Privado, la residencia habitual se corresponde con el "lugar en el que el menor tenga una cierta integración en un entorno social y familiar". Ello, habida cuenta que del término habitual se desprende "cierta regularidad o estabilidad en la residencia".

19. El TJUE también ha establecido una serie de circunstancias que habrán de tenerse presentes por el órgano jurisdiccional nacional a la hora de fijar cual es el lugar de la residencia habitual de un menor. Resumiendo dichos parámetros, de la doctrina del TJUE se colige que, si bien se requiere la presencia física del menor en un Estado miembro, no se trata de una presencia ocasional o temporal, debiendo hacer hincapié, entre otros extremos, en "las condiciones y razones de la permanencia del menor en el territorio de un Estado miembro, así como su nacionalidad".

20. Asimismo, el TJUE ha tenido en cuenta factores tales como "la duración, la regularidad, las condiciones y las razones de la estancia en el territorio de ese Estado miembro y en su caso, del traslado de la madre a este último Estado. Igualmente, se han recogido otros elementos como "la edad del menor, los orígenes geográficos y familiares de la madre, junto con las relaciones familiares y sociales que mantienen ésta y el menor en el mismo Estado miembro ${ }^{17}$.

12 Para mayor información sobre el tema, consúltese J. CARRASCOSA GONZÁLEZ, "Litigación internacional, responsabilidad parental y foro de la residencia habitual del menor en un Estado miembro. Un estudio jurisprudencial”, en M.A. CEBRIÁN E I. LORENTE Martínez (Dir.), Protección de Menores y Derecho Internacional Privado, Granada, Comares, 2019, pp.306-323, I. OtAeGuI AizPURUA, "La errónea determinación de la competencia judicial internacional cuando los hijos residen en Estados miembros diferentes: Sentencia de la AP de Lugo no 44/2018, de 11 de abril de 2019”, Cuadernos de Derecho Transnacional, (Marzo 2019), Vol. 11, $\mathrm{N}^{o}$ 1, pp. 870-876, B. CAMPUZANo Díaz, "Una nueva sentencia del TJUE sobre el concepto de residencia habitual en el marco del Reglamento 2201/2003: Sentencia de 17 de octubre de 2018, UD y XB, AS. 393/18 PPU”, en Cuadernos de Derecho Transnacional (Octubre 2019), Vol. 11, No 2, pp. 462-471 y L.A. Pérez MARÍN, "El interés superior de los niños y las niñas, de nuevo sobre la necesidad de la creación del concepto autónomo de su residencia habitual. Auto de 24 de octubre de 2019 Sección Decimosegunda de la Audiencia Provincial de Barcelona", Cuadernos de Derecho Transnacional (Octubre 2020), Vol. 12, No 2, pp. 1119-1127.

${ }_{13}$ Este artículo hay que ponerlo en relación con el art.16 RBII bis, de tal modo que, conforme a la doctrina del TJUE el "momento en que se [presenta ante un órgano jurisdiccional] el escrito de demanda o documento equivalente», con arreglo a dicha disposición, es el momento en que dicha presentación tiene lugar ante el órgano judicial de que se trate, aun cuando esa presentación no inicie por sí misma, de manera inmediata, el procedimiento según el Derecho nacional”. Vid,. ATJUE 22 de junio 2016 (C-173/16, ECLI:EU:C:2016:542).

${ }_{14}$ Es decir, en los supuestos de cambio de residencia legal de un Estado miembro a otro, el Estado miembro de la residencia precedente del menor conservará su competencia para modificar una resolución judicial sobre el derecho de visita dictada en dicho Estado miembro antes de que hubiera cambiado de residencia, con las condiciones del art.9 RBII bis; y cuando se haya producido una sustracción internacional de menores entre Estados miembros (art.10 RBIIbis)

15 La realidad es que este vacío legal está siendo integrado por la jurisprudencia de distintos órganos jurisdiccionales, particularmente, cuando han de resolver supuestos de sustracción internacional de menores. Así lo indica también, I. LORENTE Martínez, "Competencia judicial internacional de los tribunales españoles en los casos de sustracción de menores. El trato desigual en situaciones similares”, Cuadernos de Derecho Transnacional (Marzo 2019), Vol. 11, No 1, p.829.

${ }^{16}$ A este respecto, considera CARRASCOSA GonZÁLEZ que, además de una laguna, es posible concluir que el legislador europeo podría haber incurrido en un error, en tanto que no ha sabido precisar el concepto legal de residencia habitual. El citado autor valora asimismo la posibilidad de que el legislador conscientemente no haya definido este concepto, dejando este extremo a un posterior desarrollo jurisprudencial. O lo que es lo mismo, con la intención de que sean los tribunales los que lo desarrollen, atendiendo a las circunstancias de cada caso concreto. Vid. J. CARRASCOSA GonZÁLEZ, "Litigación internacional, responsabilidad parental y foro de la residencia habitual...cit", p.315.

${ }_{17}$ Vid., ente otras resoluciones, STJUE (Sala Primera) 22 diciembre 2010 (C- 497/10 PPU, ECLI:EU:C:2010:829), STJUE 
21. De la misma manera, el TJUE ha matizado que la voluntad de uno de los progenitores de convivir con el menor en el Estado miembro del que es nacional dicho progenitor no puede resultar decisiva a la hora de precisar donde se sitúa la residencia habitual del menor en el momento de presentación de la demanda. Más aún, cuando la titularidad de la guardia y custodia del menor la ostentan ambos progenitores, supuesto en el cual debe valorarse la intención de éstos por separado ${ }^{18}$.

22. Corresponde ahora dilucidar cómo se determina la competencia en materia de alimentos y si existe la posibilidad de prorrogar la competencia en favor de los órganos jurisdiccionales que resuelvan las pretensiones relativas a las cuestiones propias de la responsabilidad parental, con arreglo a los foros previstos en el RBII bis. A tal fin, habrá que acudir al Reglamento (CE) no 4/2009 del Consejo, de 18 de diciembre de 2008, relativo a la competencia, la ley aplicable, el reconocimiento y la ejecución de las resoluciones y la cooperación en materia de obligaciones de alimentos ${ }^{19}$. Según dicho Reglamento, entran dentro de su ámbito de aplicación las obligaciones de alimentos derivadas de una relación familiar, de parentesco, matrimonio o afinidad (art.1.1). El concepto de alimentos comprende todas aquellas prestaciones establecidas por la Ley para aliviar las necesidades económicas de determinadas personas y que, a su vez, se prevén a cargo de ciertos parientes o personas que poseen de mayores recursos económicos ${ }^{20}$.

23. Por lo que respecta a los foros de competencia judicial internacional previstos en el R.4/2009, resulta prevalente el de la sumisión expresa o tácita (arts.4 y 5), estableciendo asimismo una serie de foros subsidiarios y alternativos entre sí, para el caso de que las partes no hubieran elegido el tribunal competente $^{21}$ :

$\left.1^{\circ}\right)$ Residencia habitual del demandado en un Estado miembro (art.3.a).

$\left.2^{\circ}\right)$ Residencia habitual del acreedor de alimentos en un Estado miembro (art.3.b).

$3^{\circ}$ ) Foro de la competencia de la acción de estado de la persona (art.3.c).

$4^{\circ}$ ) Foro de la competencia de la acción relativa a la responsabilidad parental (art.3.d), que resulta relevante a los efectos del presente trabajo y que otorga competencia judicial internacional al concreto órgano jurisdiccional de un Estado miembro que disponga de competencia conforme a la ley del foro para el enjuiciamiento de una acción relativa a la responsabilidad parental, si la demanda de alimentos es accesoria de dicha acción. Ello, con una salvedad, que la competencia se fundamente únicamente en la nacionalidad de una de las partes ${ }^{22}$.

24. Además, el Reglamento prevé en su art. 6 un foro de competencia subsidiaria en favor de los órganos jurisdiccionales del Estado miembro del que las partes tengan su nacionalidad común, cuando ningún órgano jurisdiccional de ningún Estado miembro resulte competente con arreglo a los arts. 3, 4 y 5 y además, tampoco pueda atribuirse competencia a ningún órgano jurisdiccional de un Estado parte en el Convenio de Lugano II $^{23}$. También incorpora un foro de necesidad en el art.7.

(Sala Primera) 15 de febrero 2017 (C-499/15, ECLI:EU:C:2017:118), ATJUE (Sala Primera) de 10 abril 2018 (C-85/18, PPU CV, ECLI:EU:C:2018:220) y STJUE (Sala Primera) de 17 octubre 2018 (C393/18 PPU, ECLI:EU:C:2018:8359).

Por lo demás, la "residencia habitual" es un concepto "ficticio" o "de hecho", tal y como dispone la STJUE (Sala Quinta) 8 junio 2017 (C-111/17 PPU, ECLI:EU:C:2017:436).

18 Véase la STJUE (Sala Quinta) 28 de junio 2018 (C512/17, ECLI:EU:C:2018:513).

19 Reglamento (CE) n $4 / 2009$ del Consejo, de 18 de diciembre de 2008, relativo a la competencia, la ley aplicable, el reconocimiento y la ejecución de las resoluciones y la cooperación en materia de obligaciones de alimentos («DOUE» núm. 7, de 10 de enero de 2009).

20 Vid. J. Carrascosa González, "Tema XVi: Alimentos”, en A.L. Calvo Caravaca y J. Carrascosa González (Dir.), Compendio de Derecho Internacional Privado, Murcia, 2019, p.369.

${ }^{21}$ Consúltese de nuevo, Vid. J. Carrascosa GonZÁlez, "Tema XVI: Alimentos", cit., p.371.

22 A este respecto, Vid. STJUE 12 Noviembre 2014 (C-656/13, ECLI:EU:C:2014:2364) y ATJUE 10 Abril 2018 (C85/2018 PPU, no publicado).

${ }^{23}$ Convenio relativo a la competencia judicial, el reconocimiento y la ejecución de resoluciones judiciales en materia civil y mercantil («DOUE» núm. 339, de 21 de diciembre de 2007). 
25. Todo ello, sin olvidar que el Convenio de Lugano II dispone de un foro especial en materia de alimentos en el art.5.2 y que por lo que respecta a la norma de producción interna, el art.22 quáter $\mathrm{f}$ ) LOPJ, hay que indicar que la misma resulta inoperante.

\section{Supuestos de litispendencia internacional}

26. Puesto que el Auto de la AP de Barcelona hace referencia, aunque sea de soslayo, a la posible presencia de un caso de litispendencia internacional, muy brevemente, se realizarán algunas precisiones sobre esta materia, si bien, sin ánimo de resultar exhaustivos.

27. En el ámbito del RBII bis y en lo que se refiere a la responsabilidad parental, se contempla una regla específica en el art.19 de dicho Reglamento sobre litispendencia europea- la regla prior tempore-en cuya virtud, "cuando se presentaren demandas relativas a la responsabilidad parental sobre un menor que tengan el mismo objeto y la misma causa ante órganos jurisdiccionales de distintos Estados miembros, el órgano jurisdiccional ante el que se hubiere presentado la segunda demanda suspenderá de oficio el procedimiento en tanto no se establezca la competencia del órgano jurisdiccional ante el que se interpuso la primera". Continúa el mencionado precepto indicando que "cuando se establezca que es competente el primer órgano jurisdiccional, el segundo se inhibirá en favor de aquél", en cuyo caso, "la parte actora ante el segundo órgano jurisdiccional podrá presentar la acción ante el primero"24.

28. A los efectos de tener iniciado el procedimiento, habrá que acudir a lo dispuesto en el art.16.1, conforme al cual se considerará iniciado un procedimiento ante un órgano jurisdiccional "desde el momento en que se le presente el escrito de demanda o documento equivalente, a condición de que posteriormente el demandante no haya dejado de realizar lo necesario para que la notificación o traslado de dicho escrito o documento al demandado". O bien, "si dicho escrito o documento ha de ser objeto de notificación o traslado antes de su presentación al órgano jurisdiccional, en el momento en que lo reciba la autoridad encargada de la notificación o traslado, a condición de que posteriormente el demandante no haya dejado de realizar lo necesario para la presentación del documento al órgano jurisdiccional"25.

29. Por su parte, el R. 4/2009 también regula la litispendencia internacional en idéntico sentido en materia de obligaciones alimentarias.

30. Por último, debe indicarse que la LCJIMC recoge la litispendencia internacional en el art.39, si bien, únicamente entrará en juego en defecto de norma de la Unión de la Unión Europea o tratado

${ }^{24}$ En este punto, se ha argüido que la solución del art.19 RBII bis impulsa "una carrera hacia los Tribunales", en tanto que favorece el apresuramiento en la interposición de la demanda, al establecer que será el órgano ante el que se presentó la primera demanda el que, de resultar internacionalmente competente, resolverá la controversia. Ello, a juicio de esta corriente doctrinal, contraría las nuevas tendencias en el Derecho de familia, más proclives a que los cónyuges solventen sus controversias por la vía del acuerdo. Vid. C. GonzÁlez Beilfuss., "La nulidad, separación y divorcio en el derecho internacional privado español: cuestiones de competencia judicial internacional y ley aplicable", Cursos de Derecho Internacional y Relaciones Internacionales de Vitoria-Gasteiz, 2011, pp.155-156.

Se ha observado igualmente que la razón de ser de las reglas relativas a la litispendencia en el ámbito de la Unión Europea, tratan de evitar los procedimientos paralelos ante los órganos jurisdiccionales de diferentes Estados Miembros, así como los conflictos entre las resoluciones judiciales que se pudieran citar entre ellos, todo esto, en aras de una buena administración de justicia en la Unión, tal como ha establecido el TJUE en numerosas Sentencias. En definitiva, lo que se pretende es impedir que se dicten resoluciones claudicantes. Vid. P. Orejudo Prieto de los Mozos, "Diez años de aplicación e interpretación del Reglamento Bruselas II bis sobre crisis matrimoniales y responsabilidad parental (análisis de los aspectos de competencia judicial internacional)", La Ley. Unión Europea, núm. 21, 2014, pp.5-22.

${ }^{25}$ A este respecto, el TJUE indicó que el art.16.1 a) RBII bis no requiere en todo caso la concurrencia de estos dos requisitos, el acto inicial de presentación de la demanda o documento equivalente ante un órgano jurisdiccional y su notificación o traslado al demandado, en tanto que esta última exigencia puede modularse con una condición: que la ausencia de notificación o traslado de la demanda o documento equivalente no se deba a que el demandante haya dejado de tomar las medidas que le incumben a tal fin. Vid. ATJUE 16 julio 2015 (C-507/14, no publicado, EU:C:2015:512) y ATJUE 22 junio 2016 (C-173/16, ECLI:EU:C:2016:542). 
internacional que regule la cuestión (art.2). Ténganse en cuenta aquí igualmente lo dispuesto en el art.22 nonies, según el cual "las excepciones de litispendencia y de conexidad internacionales se alegarán y tramitarán con arreglo a las normas generales que regulen las leyes procesales".

\section{Eficacia en España de resoluciones extranjeras en las materias analizadas: Instrumentos legales aplicables}

31. A la vista de que el AAP de Barcelona de 23 de julio de 2020 menciona la vigencia en España de una resolución dictada por los órganos jurisdiccionales franceses, parece oportuno detallar de forma concisa cuáles son los instrumentos legales aplicables en relación con la validez en nuestro país de resoluciones extranjeras sobre responsabilidad parental y alimentos.

32. En primer lugar, respecto de la responsabilidad parental, cuando se trate de resoluciones dictada por autoridades y tribunales de Estados miembros, con excepción de Dinamarca, habrá que acudir a los arts. 23-38 RBII bis.

33. En segundo término, también en relación con los litigios que tengan por objeto la responsabilidad parental y en aquellos supuestos que no quedan cubiertos por el RBII bis, es decir, cuando se trate de resoluciones de terceros Estado que sean parte del CH 1996, operarán los art.23 a 28 del citado Convenio. Ello, sin perjuicio de los Convenios bilaterales que, en su caso, pudieran resultar de aplicación.

34. Por su parte, en el ámbito de la Unión Europea y en materia de alimentos, la cuestión tratada en el presente epígrafe se regula en los arts.16 a 38 R.4/2009.

35. En defecto de los anteriores textos legales, se aplicarán los arts.46-61 LCJIMC.

36. Dicho esto, lo determinante a los efectos del presente trabajo es que, en virtud del mecanismo del reconocimiento, la decisión extranjera surtirá efectos procesales en nuestro país, de tal manera que desarrollará los efectos de cosa juzgada material, el efecto constitutivo y el efecto de tipicidad ${ }^{26}$.

37. En particular, hay que precisar que el efecto de cosa juzgada material comporta que la resolución extranjera vincula a las autoridades y tribunales españoles como si se tratase de una decisión adoptada por los tribunales españoles (efecto pòsitivo). Junto a ello, el efecto negativo de cosa juzgada material supone que no cabe formular ante las autoridades y órganos jurisdiccionales españolas el mismo asunto, ya resuelto por el tribunal o autoridad extranjera.

38. En cuanto al efecto constitutivo, significa que, obtenido el reconocimiento, la relación jurídica objeto de la resolución se considera existente en nuestro sistema jurídico.

39. Por último, el efecto de tipicidad hace referencia a si la decisión extranjera puede incardinarse en los conceptos que se contemplan en las normas españolas, como pudieran ser los de "sentencia firme" o "resolución judicial".

\section{Análisis del fallo del AAP Barcelona 23 julio 2020}

40. Procede ahora examinar las cuestiones litigiosas a la luz de la normativa aplicable, con el fin de dilucidar si la actuación de la Audiencia Provincial de Barcelona es ajustada a Derecho.

${ }^{26}$ Sobre este particular, véase A.L. Calvo Caravaca y J. Carrascosa González, Derecho Internacional Privado...cit., pp.383-387. 
41. Comenzando por la decisión dictada por el Juzgado de Primera Instancia, cabe resaltar que, de los poco claros fundamentos del Auto de la Audiencia Provincial de Barcelona, que no facilita todos los datos, se desprende que nos encontramos ante un supuesto en el cual se han formulado varias demandas en relación con un supuesto de responsabilidad parental entre las mismas partes, con el mismo objeto y la misma causa. Si bien, los razonamientos del fallo no permiten establecer si el Juzgado "a quo" ha analizado si se cumplen dichos extremos o por el contrario, se trataría de demandas diferentes.

42. En este punto, hay que resaltar el absoluto desconocimiento que demuestra el Juzgado de Primera Instancia español del sistema de fuentes de Derecho Internacional Privado vigente en nuestro país, toda vez que resuelve la cuestión con arreglo a lo dispuesto en el art.39 LCJIMC, estimando la declinatoria por falta de competencia internacional y suspendiendo el procedimiento al amparo del citado artículo. En efecto, como se ha puesto de relieve más arriba, el art.39 LCJIMC regula los supuestos de litispendencia internacional, si bien, solamente entrará en juego en defecto de norma internacional, de la Unión Europea o convencional que regule la cuestión. El Juzgado obvia, por tanto, que nos encontraríamos ante un caso de litispendencia europea, cuya solución dependerá de lo previsto en el art.19 del RBII bis, en relación con el art.16 del mismo texto legal, el cual prevalece sobre nuestra norma de producción interna. Ello, habida cuenta los elementos internacionales presentes en la situación, puesto que, al parecer, existía otra resolución previa de un órgano jurisdiccional francés, declarando su competencia judicial internacional para el enjuiciamiento del caso, lo que motivó que otro Juzgado español también se declarase incompetente en favor de aquél.

43. Entrando ya a valorar el Auto que resuelve el recurso de apelación, debe observarse que la Audiencia Provincial para determinar la competencia judicial de los Juzgados de Barcelona se remite a la LOPJ y a la LEC en aquellos supuestos en los que las partes son nacionales y residentes en España, incluidos los menores. En este punto, habrá que entender que, tratándose de situaciones meramente internas, la referencia a la LOPJ no lo es a las normas de competencia judicial internacional previstas en los arts 22 a 22 nonies LOPJ, sino a las reglas sobre competencia objetiva, funcional y territorial previstas en las leyes procesales españolas.

44. Respecto de las situaciones que presentan un elemento internacional, la Audiencia utiliza el término "punto de conexión", propio de las normas de conflicto a través de la cuales se determina el derecho aplicable y que no resulta correcta cuando a lo que se está haciendo referencia es a los criterios de atribución de competencia judicial internacional. A este respecto, sí que lleva razón el Tribunal "ad quem" cuando otorga prevalencia a las normas de la Unión Europea y a los Convenios internacionales sobre la LCJIMC, extremo éste que, además, se contempla en el art.2 de la propia LCJIMC. Aquí, merece una valoración muy positiva la mención que hace la Audiencia al Derecho de la Unión Europea como un Derecho procesal diferenciado y a la consideración del Juez español como Juez europeo, que aplica las normas procesales europeas con preferencia a las de producción interna ${ }^{27}$.

45. Acertada es también la decisión de la Audiencia Provincial de Barcelona de acudir al RBII bis a fin de determinar si los tribunales españoles resultan internacionalmente competentes para conocer de la demanda por la cual la recurrente solicita la patria potestad compartida por ambos progenitores, la guarda de la menor a favor de la madre, el establecimiento de un régimen de visitas respecto del padre, el establecimiento del domicilio de la niña en el de su madre y la pensión de alimentos y abono de gastos extraordinarios de la menor. Sin embargo, no puede considerarse correcto el argumento de que el Reglamento se aplica porque hay casos de Derecho Civil relativos a la atribución, ejercicio, delegación, restricción o restricción de la responsabilidad parental, en los cuales se encuentra implicados varios países. Ello, por cuanto ya se ha visto que el Reglamento se aplica, no por el hecho de que la situación se encuentre vinculada con distintos países, cualquiera que estos sean, sino que opera cuando el menor

${ }^{27}$ Véase el comentario que hace J. CARrascosa GonZÁlez respecto del AAP Barcelona 22 mayo 2019, en el cual el Tribunal realiza una consideración similar. http://www.accursio.com/private/uploads/Noticias_Accursio_2020_-_006_006_006.pdf. 
reside en un Estado miembro de la Unión Europea y en este caso, con preferencia a otros instrumentos internacionales, como el CHA 1996 y el art.22 quáter LOPJ.

46. Nada hay que objetar al análisis que lleva a cabo la Audiencia acerca de los arts. 8 y ss. RBII bis y en particular, por lo que respecta a los arts.8 y 9. Ciertamente, en materia de responsabilidad parental, tal como se ha expuesto más arriba, la competencia judicial internacional ha de recaer como regla general sobe los órganos jurisdiccionales del Estado miembro de la residencia habitual del menor en el momento en el que se presenta el asunto ante el órgano jurisdiccional, conforme al art.8. Ello, dado que dichos tribunales se encuentran en mejor situación para conocer del litigio, atendiendo al principio del interés del menor y al principio de proximidad.

47. Por lo demás, como muy bien dice la Audiencia, el art.9 RBII bis, que opera como excepción a la regla general del art.8, no resulta de aplicación en el presente caso, dado que no se pretende la modificación de una resolución sobre los derechos de visitas dictada por los tribunales franceses, correspondientes a la residencia habitual anterior de la menor.

48. Al contrario que el Juzgado de Primera Instancia, la Audiencia no entra a dilucidar expresamente si se ha producido un supuesto de litispendencia internacional ni la normativa que regularía dicho problema. En este sentido, el Tribunal "ad quem" se limita a solventar la cuestión concluyendo que la competencia judicial internacional para entrar a conocer del litigio en cuestión corresponde a los Tribunales españoles, dado que la menor reside en España y estimando que, en el momento de interposición de la demanda, no se había dictado resolución alguna, ni por los órganos jurisdiccionales españoles ni por los franceses que atribuyese la guarda de la hija menor a cualquiera de sus progenitores o impidiese a la niña la salida del país vecino. A este respecto, hay que hacer notar que la Audiencia Provincial tampoco analiza los parámetros que acreditan que la residencia de la hija menor se sitúa en nuestro país y no en Francia.

49. Ahora bien, se olvida la Audiencia Provincial de que la demanda de la que trae causa el recurso de apelación examinado incluye asimismo una pretensión relativa a la pensión de alimentos que el padre debe pagar a la hija menor. Recuérdese aquí que las obligaciones sobre alimentos quedan excluidas del RBII bis (art.1.3.c) y que para determinar la competencia judicial internacional habría que acudir al R.4/2009, que, conforme al art.3.d), atribuye competencia judicial internacional al concreto órgano jurisdiccional de un Estado miembro que disponga de competencia conforme a la ley del foro para el enjuiciamiento de una acción relativa a la responsabilidad parental, si la demanda de alimentos es accesoria de dicha acción. Ello, con una salvedad, que la competencia se fundamente únicamente en la nacionalidad de una de las partes, lo que no acontece en el presente caso, en el cual se determina la competencia en función de la residencia habitual de la menor, conforme al foro del art.8 RBII bis.

50. Concluye la Audiencia Provincial examinando la eficacia que ha de otorgarse a la Sentencia del Tribunal de apelación de Montpellier, por la que se acuerda mantener a los progenitores en el ejercicio conjunto de la patria potestad sobre la menor, fijar el domicilio de la niña en el de la madre y disponer un régimen de visitas respecto del padre. Recuérdese que en el Auto estudiado se dice que la propia Audiencia Provincial otorgó plena vigencia en España a la resolución francesa, de donde se deduce que fue objeto de reconocimiento en nuestro país.

51. Sobre este particular, hay que recordar que, tratándose de una decisión judicial dictada en materia de responsabilidad parental por los Tribunales de un Estado miembro, su reconocimiento debió llevarse a cabo por los cauces establecidos en el RBII bis. Del mismo modo, tampoco puede desconocerse que, como consecuencia de ello, la resolución francesa desplegará en España los efectos procesales de cosa juzgada material, constitutivos y de tipicidad. De ahí que la Audiencia recalque que las cuestiones atinentes a la menor que no fueron resueltas por la decisión dictada por los Tribunales franceses deberán ser objeto de enjuiciamiento por parte del Juzgado de Primera Instancia, una vez haya declarado 
su competencia judicial internacional para conocer de la demanda objeto de las presentes actuaciones. Ello por cuanto, en particular, el efecto de cosa juzgada material impediría que los Tribunales españoles entrasen a conocer sobre aquellos extremos respecto de los cuales ya existen pronunciamientos expresos en la resolución francesa, y toda vez que, conforme a dicho efecto, la resolución francesa vincularía a los Tribunales españoles como si se tratase de una resolución española.

52. Por último, cabe indicar que el Tribunal "ad quem" no ha tenido en cuenta que, si el Juzgador de Primera Instancia no puede enjuiciar las peticiones de la demanda relativas a la responsabilidad parental, porque fueron todas ellas objeto de pronunciamiento por la decisión francesa, la única pretensión respecto de la cual podría entender sería la correspondiente a los alimentos. En consecuencia, la pretensión de alimentos ya no se encontraría vinculada con la demanda de responsabilidad parental y por consiguiente, la competencia judicial internacional de los Tribunales españoles no podría determinarse de acuerdo con el art. 3 d) R.4/2009. En este sentido, en defecto de sumisión expresa o tácita (arts.4 y 5), los tribunales españoles dispondrían de competencia judicial internacional en materia de alimentos, en virtud del art.3.b) R.4/2009, puesto que la residencia habitual del acreedor de alimentos, es decir, de la hija menor, se encuentra en nuestro país.

\section{Reflexiones finales}

52. Como puede desprenderse tras analizar el Auto de la Audiencia Provincial de Barcelona de 23 de julio de 2020, la presencia de un elemento extranjero en procedimientos como el examinado plantea problemas desde la perspectiva del Derecho Internacional Privado. En especial, en el presente caso, por lo que respecta a la determinación de la competencia judicial internacional para el enjuiciamiento del litigo y para solventar otras cuestiones vinculadas con el supuesto en cuestión.

53. Estudiando los fundamentos de la citada resolución, resulta obvio que la existencia de una pluralidad de fuentes dificulta en gran medida la labor de todos los profesionales del Derecho, incluidos los Jueces y Magistrados. Por este motivo, es fundamental el buen manejo de las normas en orden a evitar planteamientos erróneos en la práctica profesional y en particular, por lo que respecta a nuestros Juzgados y Tribunales. A este respecto, se ha podido comprobar como los órganos jurisdiccionales españoles, en ocasiones, desconocen el sistema de fuentes propio del Derecho Internacional Privado, así como los instrumentos legales aplicables a las categorías jurídicas implícitas en la situación enjuiciada.

53. En este punto, cabe destacar la profusa labor del legislador de la Unión Europea, que se traduce en lo que se ha venido a denominar "comunitarización" o "europeización" del Derecho Internacional Privado, lo que requiere la continua intervención del TJUE, a fin de interpretar las normas con origen en el legislador de la Unión Europea ${ }^{28}$. Ello se ha dejado notar en el caso estudiado, para cuya resolución resultan aplicables las reglas del RBII bis y del R.4/2009, con arreglo al principio de primacía del Derecho de la Unión Europea sobre la normativa de producción interna.

54. En definitiva, dejando al margen los errores o imprecisiones de que adolece la resolución estudiada, del Auto de la Audiencia Provincial de Barcelona analizado cabe resaltar una cuestión ciertamente relevante, cual es que, en supuestos como el que nos ocupa, justamente, en virtud del principio de prevalencia del Derecho Internacional Privado de la Unión Europea, el Juez español ha de actuar como un auténtico Juez europeo en aplicación de normas como el RBII bis o el R.4/2009, examinadas en el presente trabajo ${ }^{29}$.

${ }^{28}$ Vid. A. Borrás Rodríguez, "La comunitarización del derecho internacional privado: pasado, presente y futuro", Cursos de Derecho Internacional y Relaciones Internacionales de Vitoria-Gasteiz, 2001, p.289

${ }^{29}$ Vid .J. CARRASCOSA GonZÁLeZ, http://www.accursio.com/private/uploads/Noticias_Accursio_2020_-_006_006_006.pdf. 